\title{
Molecular and Radiological Features of Microsatellite Stable Colorectal Cancer Cases With Dramatic Responses to Immunotherapy
}

\author{
BRIDGET P. KEENAN ${ }^{1}$, KATHERINE VAN LOON ${ }^{1}$, ANURADHA D. KHILNANI ${ }^{2}$, \\ NICHOLAS FIDELMAN ${ }^{3}$, SPENCER C. BEHR ${ }^{3}$, CHLOE E. ATREYA ${ }^{1}$ and DAVID Y. $\mathrm{OH}^{1}$ \\ ${ }^{1}$ Division of Hematology/Oncology, Department of Medicine, University of California, San Francisco, CA, U.S.A.; \\ ${ }^{2}$ Merck \& Co., Inc., Kenilworth, NJ, U.S.A; \\ ${ }^{3}$ Department of Radiology and Biomedical Imaging, University of California, San Francisco, CA, U.S.A.
}

\begin{abstract}
Background/Aim: The majority of colorectal cancer (CRC) cases, which are microsatellite stable (MSS) and do not harbor mismatch repair deficiency/microsatellite instability, are resistant to immunotherapy. Identification of patients with exceptional responses in MSS CRC and predictive biomarkers is an unmet need that needs to be addressed. Case Report: We report three cases of MSS CRC with durable clinical benefit from immunotherapy with anti-PD-1 checkpoint inhibitors. Two cases bear a POLE P286R mutation, which has been associated with lack of immunotherapy response in MSS CRC. Two cases bear alterations in Ataxia-Telangiectasia Mutated (ATM) which may contribute to observed responses, including interaction with a co-administered intratumoral stimulator of interferon genes (STING) pathway agonist in one patient. Conclusion: Novel DNA damage repair alterations, including mutations in ATM, can provide insight into additional mechanisms by which genomic alterations can sensitize MSS CRC to diverse immunotherapies.
\end{abstract}

Colorectal cancer (CRC) ranks in the top five cancer types in terms of incidence and mortality worldwide (1). In the minority of CRC tumors with microsatellite instability or mismatch repair deficiency (MSI/MMRd), response rates to checkpoint inhibitors (CPI) blocking PD-1 or CTLA-4 range from 30-55\%, leading to their approval, whereas microsatellite stable/mismatch repair proficient colorectal cancer (MSS/pMMR CRC) has a near-zero

This article is freely accessible online.

Correspondence to: David Y. Oh, MD, Ph.D., University of California, 513 Parnassus Avenue, HSE301, Box 0519, San Francisco, CA 94143, USA. Tel: +1 4155149301, e-mail: David.oh@ucsf.edu

Key Words: Immunotherapy, checkpoint inhibition, colorectal cancer, DNA damage. response rate (2-4). However, there are indications that CPI can benefit MSS CRC patients; a phase II trial of anti-PD-L1 plus anti-CTLA-4 demonstrated an overall survival benefit for MSS CRC compared to best supportive care, despite few objective responses (5).

Identifying exceptional MSS CRC responders to CPI is critical, but our knowledge of biomarkers that predict these responses is incomplete. Although pembrolizumab was recently approved for tumor mutational burden (TMB)-high $[\geq 10$ mutations/megabase (MB)] advanced cancers agnostic of tumor type, based on the KEYNOTE-158 study, this study did not include CRC patients (6), and response rates for TMB-high MSS CRC patients (defined as $\geq 9$ mutations/MB) are known to be low (11\%) (7).

Mutations in genes involved in DNA replication (such as POLE or POLD1) that create a hyper-mutated (but MSS) phenotype have been associated with durable response to CPI, including in CRC, but not all POLE mutations predict CRC response (8-11). In particular, the common proofreading P286R mutation did not demonstrate CPI response in MSS CRC and was associated with low $\mathrm{CD}^{+}$tumor infiltration, indicating that this mutation did not sensitize immune responses to these tumors (11). Other alterations in DNA damage repair (DDR) pathway genes have also been posited to predict immunotherapy responses in retrospectively analyzed cohorts (12). We present here three cases with perturbations involving DNA replication and/or DDR pathways, two with high TMB associated with POLE P286R, but also two with separate mutations in ATM which may interact with a co-administered STING pathway agonist.

\section{Case Report}

Case 1. A 28-year-old female presented with diarrhea, fatigue, and anemia. A diagnostic colonoscopy showed a near-obstructing mass in the transverse colon, with biopsies confirming poorly 

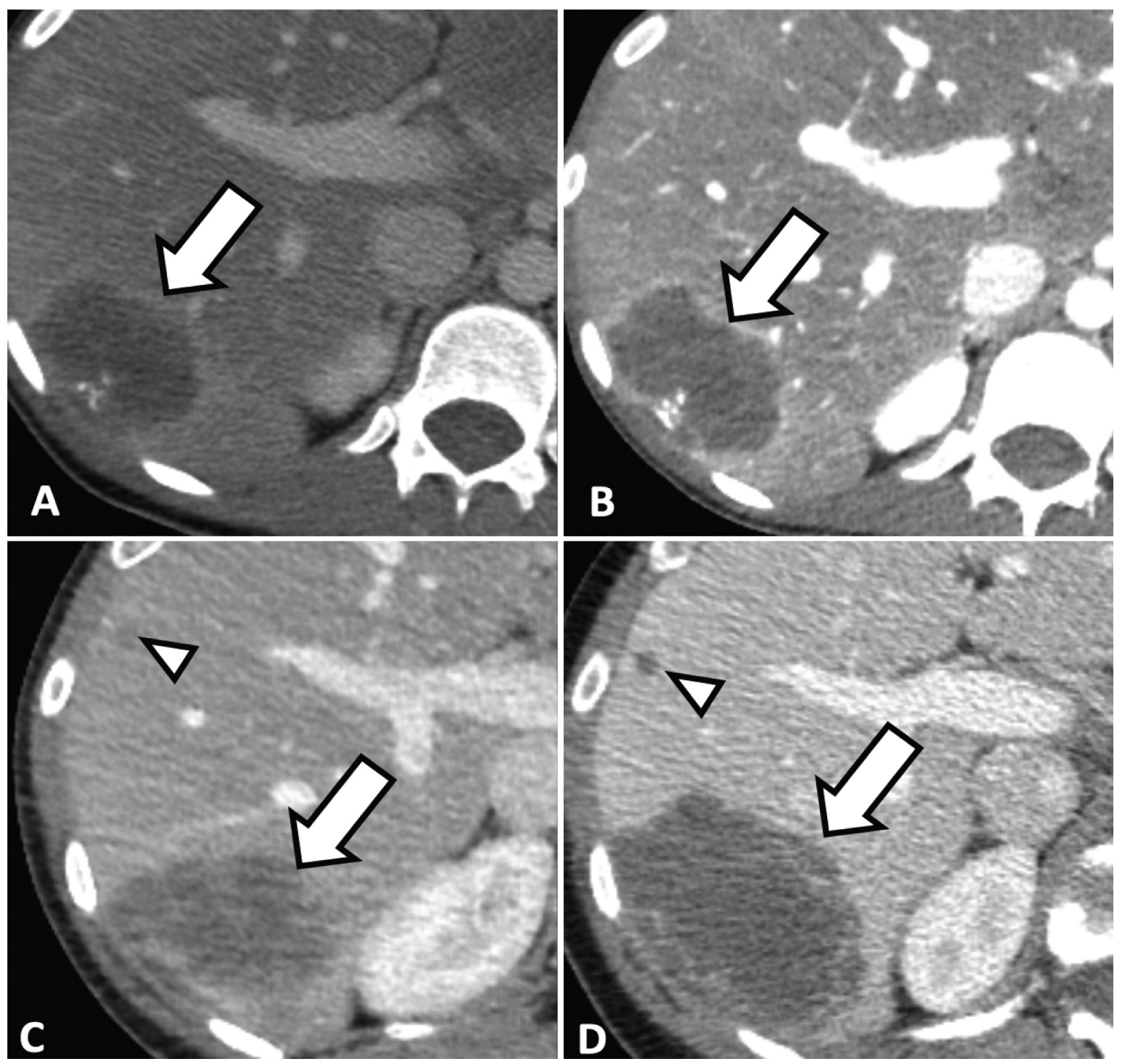

Figure 1. (A) Axial post contrast CT image through the liver showing the peripherally enhancing $4.8 \mathrm{~cm}$ right hepatic lobe metastasis with internal calcifications (white arrow). (B) CT performed after right hemicolectomy showing increased size of the right hepatic lobe metastasis (white arrow) to $5.5 \mathrm{~cm}(36 \mathrm{HU})$. (C) First follow-up CT after induction of immunotherapy demonstrating continued increase size of right hepatic lobe metastasis now measuring $6.4 \mathrm{~cm}$ (white arrow, $33 \mathrm{HU}$ ). Additionally, there is a new subtle $0.6 \mathrm{~cm}$ lesion just anterior to this (white arrowhead). (D) Second follow-up CT after initiation of immunotherapy demonstrating increased size of the right hepatic lobe metastasis measuring $7.7 \mathrm{~cm}$, but increasing central necrosis (26 HU). A smaller lesion (white arrowhead) is again seen, but more well-defined due to the interval necrosis.

differentiated pMMR adenocarcinoma. Imaging revealed synchronous liver masses (largest $4.8 \mathrm{~cm}$, Figure 1A). She received 4 cycles of neoadjuvant FOLFOX, with a subsequent CT scan revealing progression of liver metastases (Figure 1B). Resection of the colon mass revealed scant residual tumor cells in the primary site and 34 negative lymph nodes. Germline testing was negative; however, UCSF500 tumor molecular profiling demonstrated POLE (P286R) mutation, MSS, and high TMB (198.8 mutations/MB; Table I).
She was treated post-operatively with nivolumab $3 \mathrm{mg} / \mathrm{kg}$ plus ipilimumab $1 \mathrm{mg} / \mathrm{kg}$ every 3 weeks (for 4 doses) followed by nivolumab every 2 weeks. After 4 cycles of combined CPI, re-imaging showed continued growth in the largest liver metastases, with peripheral coarse calcification, enhancing internal rim, and hypoattenuating outer rim (Figure 1C-D). She subsequently underwent partial hepatectomy; pathology from the surgical specimen demonstrated mucin with inflammatory cells and no detectable tumor. 
Table I. Summary of microsatellite status, tumor mutational burden, and somatic mutations.

\begin{tabular}{|c|c|c|c|}
\hline Gene or molecular feature & Case 1 & Case 2 & Case 3 \\
\hline Microsatellite status & MSS & MSS & MSS \\
\hline Tumor mutational burden & 198.8 mutations/MB (high) & 168 mutations/MB (high) & 9 mutations/MB (intermediate) \\
\hline APC & $\mathrm{R} 1273 *, \mathrm{~S} 1503 *, \mathrm{R} 2204 *$ & E1577*, L68*, S1222*, R2237* & P692fs*26, T1556fs*3 \\
\hline POLE & P286R & P286R & - \\
\hline ATM & - & ATM R250* - subclonal & S2408L \\
\hline TP53 & - & $\mathrm{F} 270 \mathrm{~S}$ & G245S, P190L \\
\hline Others & & 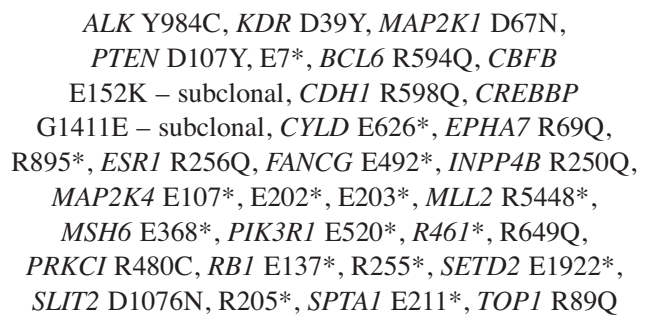 & $\begin{array}{c}\text { KRAS G13D, NF1 C2453*, } \\
\text { PIK3CA E545G, ACVR1B } \\
\text { R420*, DDR1 R514C, } \\
\text { FAM123B I332fs*45, } \\
\text { FANCC } \\
\text { Truncation exon } 8\end{array}$ \\
\hline
\end{tabular}

MSS: Microsatellite stable; MB: megabase; *stop codon.

Case 2. A 37-year-old male developed abdominal pain with 20-pound weight loss. A colonoscopy revealed a mass in the ascending colon, and biopsies confirmed a mucinous poorly differentiated adenocarcinoma. Right hemicolectomy revealed a stage IIIC tumor (pT4aN2b) with a positive visceral peritoneal margin and 24 out of 24 positive lymph nodes. After 8 cycles of adjuvant capecitabine and oxaliplatin, imaging revealed metachronous liver metastases, prompting the initiation of FOLFIRI and bevacizumab. Following progression in liver metastases and a subsequent referral to our institution, Foundation One testing revealed a POLE (P286R) mutation, an ATM mutation (predicted loss of function), and an MSS, hyper-mutated phenotype (168 mutations/MB; Table I). Germline testing did not reveal pathogenic mutations. After treatment with 4 cycles of pembrolizumab, imaging showed stability in the liver metastases with some growth in retroperitoneal and gastrohepatic lymph nodes, although with decreased attenuation, compared to pre-treatment scans (Figure 2A-B). Over the course of the following two years, the patient completed 49 cycles of pembrolizumab (two years) with subsequent tumor shrinkage (Figure 2C). Imaging three months after discontinuation of therapy showed continued decrease in liver metastases and lymph nodes (Figure 2D). During pembrolizumab, CEA decreased from baseline of 13.4 to $2.2 \mu \mathrm{g} / 1$ (reference, normal $<5.1 \mu \mathrm{g} / \mathrm{l}$ ).

Case 3. A 53-year-old woman presented with a $5 \mathrm{~cm}$ partially obstructing cecal mass and metastatic liver lesions. Biopsy of the cecal mass demonstrated poorly differentiated adenocarcinoma. Foundation One tumor molecular profiling revealed a potentially pathogenic ATM mutation, TMB 9 mutations/MB, and MSS (Table I). She initiated 5fluorouracil and oxaliplatin (FOLFOX) with a mixed response, then 5-fluorouracil and irinotecan (FOLFIRI) with bevacizumab with stable disease. She underwent right hepatectomy and right colon resection with negative margins, but residual disease was confirmed. Following surgery, she developed an anastomotic leak and post-operative chemotherapy was deferred. She subsequently underwent microwave ablation of two hepatic lesions. Prior to treatment with immunotherapy, scans showed enlarging liver metastases and new sub-centimeter lung nodules (Figure 3A). She was enrolled in a phase I clinical trial of intra-tumoral MK-1454, a STING agonist, which was injected into a single segment 3 liver metastasis at a dose of $540 \mu \mathrm{g}$ weekly for 6 weeks then every 3 weeks, with $200 \mathrm{mg}$ i.v. pembrolizumab every three weeks. After three cycles, CT scans showed decrease in pulmonary nodules and increased size of liver lesions (Figure 3B), although there was marked central necrosis and decreased attenuation. Study treatment was discontinued. Her CEA had risen while on study (CEA pre-treatment: 29.6, peak on-treatment: 72 , normal: $<5.1 \mu \mathrm{g} / \mathrm{l})$. CT scans obtained 3 and 5.5 months after the last on-study treatment showed regression in liver metastases with further decreased attenuation and no new lesions (Figure 3C and 3D); CEA and liver enzymes had also returned to normal limits. At 9 months post-treatment without any further cancer-directed therapy, she had continued regression, no abnormal uptake in liver or other regions on PET/CT, and no tumor-associated mutations detectable on Guardant 360 blood test.

Disclaimers. Human investigations were performed after approval by local Ethics Committee. All patient data presented within is de-identified and written consent was obtained from patients to use their images. 


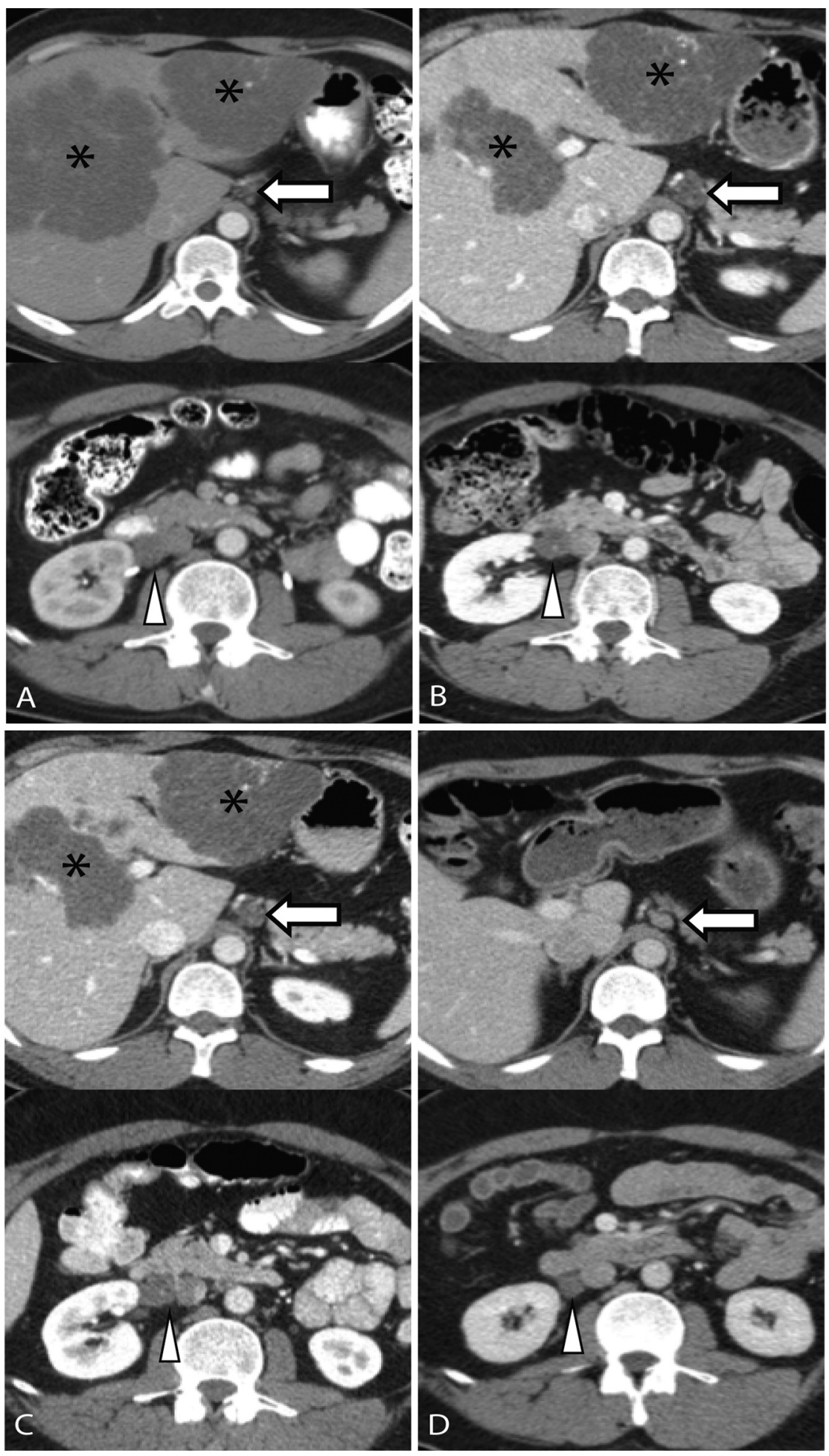

Figure 2. Axial CT images from two different levels, one through the region of upper abdomen (top) and another in the mid-abdomen (bottom) at four different time points. (A) Baseline CT images prior to initiation of immunotherapy shows the treated liver metastases (*) and an enlarged right pericaval lymph node (arrowhead) measuring up to $1.9 \mathrm{~cm}$ (37 HU). (B) CT images four months following immunotherapy showing new gastrohepatic lymphadenopathy (white arrow, $27 \mathrm{HU}$ ) as well as slight increase in right pericaval lymph node now measuring $2 \mathrm{~cm}$ in short axis (arrowhead, 32 HU). Liver metastases (*) were not significantly changed.(C) Six-month follow-up CT showing slight decrease of both the retroperitoneal (arrowhead, $36 \mathrm{HU}$ ) and gastrohepatic lymph nodes (arrow, $27 \mathrm{HU}$ ). (D) Follow-up CT three years after immunotherapy demonstrating decreased size of the retroperitoneal $(26 \mathrm{HU})$ and gastrohepatic lymph nodes $(11 \mathrm{HU})$. Liver metastases (not shown) also decreased in size. 

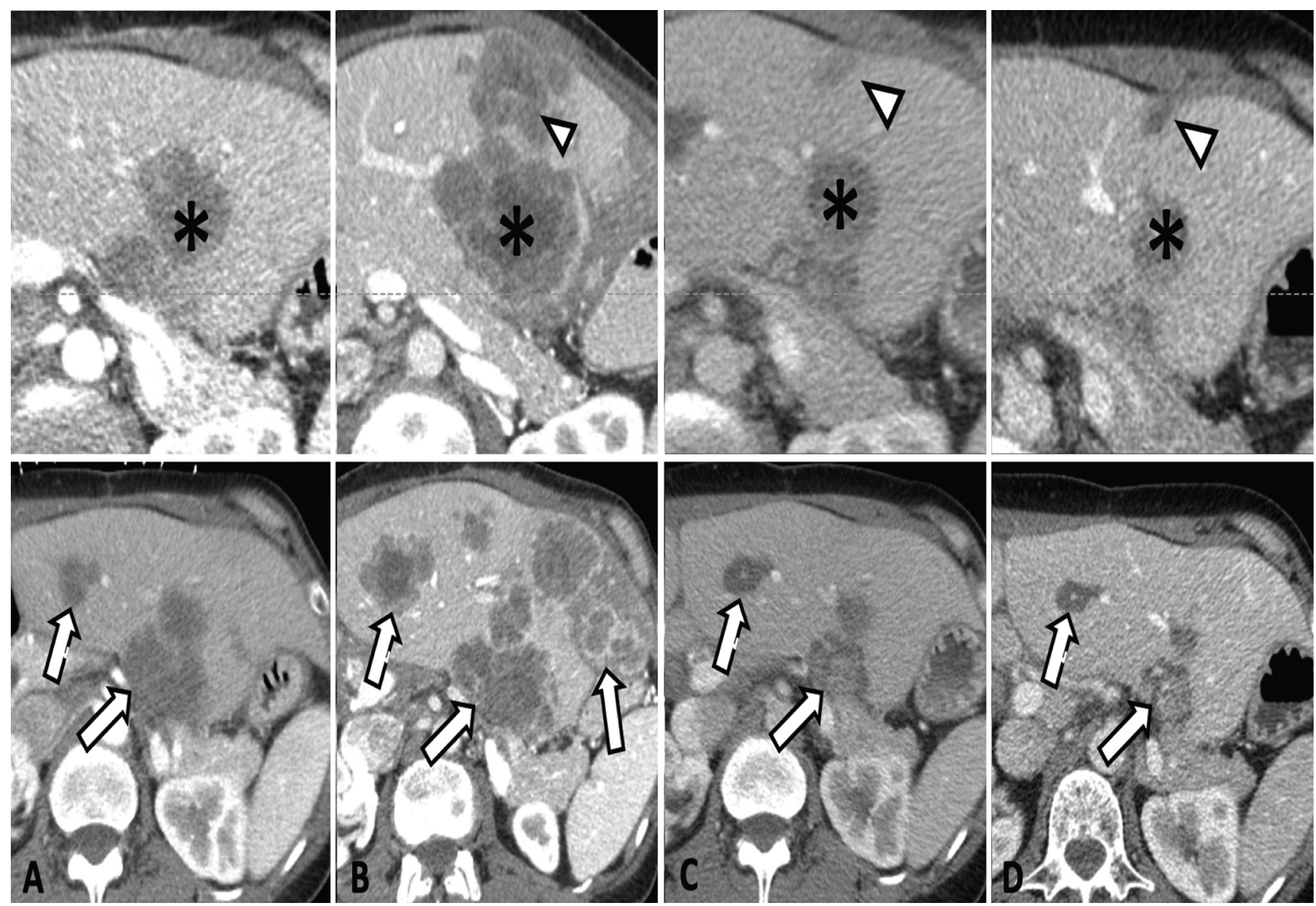

Figure 3. Top image is an axial CT image through the segment 3 lesion that had percutaneous injection. Bottom image is a separate CT image showing examples of other liver metastases. (A) Baseline CT image showing the $3.3 \mathrm{~cm}$ hepatic segment 3 metastasis [*, 49 Hounsfield units (HU)] as well as multiple adjacent hepatic metastasis (arrows). (B) CT images 2 months following initiation of the therapy showing increase in size of the hepatic metastases (white arrows) with injected lesion now measuring up to $5.9 \mathrm{~cm}$ with central necrosis (*,43 HU) as well as new liver metastasis (white arrowhead). (C) Follow-up CT 3 months after cessation of therapy (4.5 months after initiation of therapy) demonstrating decreased hepatic metastases with segment 3 metastasis (*) now measuring $3.1 \mathrm{~cm}(37 \mathrm{HU})$. Other liver metastases have also decreased in size. (D) Images 5.5 months after cessation of therapy ( 7 months after initiation of treatment) showing continued decrease in size as well as development of internal calcifications.

\section{Discussion}

Given the inherent resistance of most MSS CRC to CPI, small subsets of responders can provide valuable insight into mechanisms of response. Tumors with DDR pathway alterations may have a more immunogenic phenotype due to an increased number of mutations and neo-antigens (13). In breast, ovarian, and pancreatic tumors, increased tumorinfiltrating lymphocytes and immunogenic gene signatures within tumors have been associated with DDR mutations (13). However, it has also been demonstrated in BRCA1/2mutated breast cancer that tumors had less immune cell infiltration and evidence of $\mathrm{T}$ cell cytolytic activity, despite higher TMB and the presence of neoantigens (14). This underscores the importance of looking beyond the quantity of antigens generated by specific DDR pathway alterations to the quality of putative antigens that are produced, which can be crucial to immunotherapy response (15). This is particularly relevant in MSI/MMRd tumors, in which insertion-deletion (indel) mutations contribute to responsiveness to immunotherapy $(16,17)$, but also in MSS/pMMRd CRC as in this report, where high TMB alone does not confer response (7). Hence MSS CRC patients with non-MMR DDR alterations and exceptional CPI response can reveal other potential predictive biomarkers, but specific mutations must be carefully weighed against existing data (in the context of that tumor type) that they can associate with anti-tumor immunity and CPI response.

Two of our reported cases (Cases 1 and 2) bear the POLE P286R mutation, with a hypermutated phenotype (TMB $>100$ 
mutations/ $\mathrm{MB}$ ) indicating that this is a functional mutation, in agreement with other reports (18). While cases of POLEmutated MSS CRC that sustained durable clinical benefit from immunotherapy have been reported $(8,11,19)$, evidence for the association of specific POLE alterations and CPI response are scant. However, in available data, the POLE P286R mutation found in our patients was associated with CPI nonresponse and low $\mathrm{CD}^{+} \mathrm{T}$ cell infiltration in 2 other MSS CRC patients, directly indicating that neither this POLE alteration nor the associated high TMB were immunogenic (11). In an analysis associating pathogenic POLE mutations with immunotherapy response, there were many co-occurring mutations in DDR genes (10). While we cannot exclude a possible contribution of high TMB and/or POLE P286R alterations to responses in our patients, definitive evidence for their predictive value awaits prospective trials of MSS CRC patients with these biomarkers, and underscores the possibility that other DDR alterations may be responsible for the responses we observed.

An alternate explanation may involve alterations in the ATM pathway. Two cases presented herein (Cases 2 and 3) had somatic ATM mutations, a protein that orchestrates the repair of DNA double-stranded breaks (20). In particular, Case 3 had neither high TMB nor POLE alterations, pointing to a possible role for ATM. In addition to receiving pembrolizumab, this patient was also given intratumoral injections with MK-1454, a cyclic dinucleotide that activates the STING pathway and has shown efficacy in several tumor types $(21,22)$. Intriguingly, in both mice and patient samples, ATM deficiency leads to enhanced type I interferon signaling in response to unrepaired DNA damage, in a manner dependent on STING pathway activation $(23,24)$. Hence, this particular case highlights that in the absence of MSI, high TMB, or POLE alterations, ATM loss could synergize with immunotherapy targeting the STING activation pathway in conjunction with CPI. Perturbations in ATM may also synergize with other DDR mutations to promote response (25), as in Case 3's co-occurring mutations in TP53 and FANCC (26). It is also noteworthy that the MK-1454 was injected into liver metastases, as the presence of liver metastases has been associated with decreased response to CPI (27). Delivering immunotherapy directly to liver metastases is one approach to address this possible barrier to efficacy.

An additional feature of these cases was initial growth of tumors followed by shrinkage or stabilization of tumor size (pseudoprogression) $(28,29)$. In clinical trials of intratumoral immunotherapy, progression before response including development of new lesions has been noted in patients who ultimately responded $(30,31)$. In this series, pseudoprogression was accompanied by decreased attenuation and progressive necrosis. Changes in CT attenuation correlating with tumor necrosis may be a feature of both targeted therapies and immunotherapy $(32,33)$.
In conclusion, we present three MSS/pMMR CRC cases with sustained dramatic responses to CPI. While two cases harbored known functional alterations in POLE (P286R), with associated hypermutated phenotype, these alterations are not necessarily predictive of response in MSS CRC based on published reports. We identified potentially pathogenic mutations in other DDR pathway genes, notably ATM, which may be responsible for exceptional CPI responses in MSS CRC, including synergy with a STING pathway agonist. Exploration of additional mechanisms that confer response to immunotherapy in CRC is crucial to turning challenges into opportunities.

\section{Conflicts of Interest}

Dr. Anuradha Khilnani is a paid employee of Merck. Dr. Nicholas Fidelman, Dr. Chloe Atreya, and Dr. David Oh receive research funding from Merck (Merck \& Co., Inc., Kenilworth, NJ, USA). The rest of the authors declare no potential conflicts of interest. Dr. Katherine Van Loon: research funding: Celgene Cancer Care Links; paid consultant: Amgen. Dr. Nicholas Fidelman: research funding: Sirtex Medical, Boston Scientific. Dr. Spencer Behr: advisory board member: Advanced Accelerator Applications (AAA); paid consultant: Cancer Targeting Technologies (CTT). Dr. Chloe Atreya: research funding (institution): Bristol-Meyers Squibb, Novartis, Guardant Health, Kura Oncology; advisory board member: Pionyr Immunotherapeutics, Array Biopharma. Dr. David Oh: research funding: Roche/Genentech, PACT Pharma; paid consultant: Maze Therapeutics. Research support: Dr. Oh is funded by the National Institute of Allergy and Infectious Diseases (K08AI139375).

\section{Authors' Contributions}

B.P.K., C.A., and D.Y.O. conceptualized the manuscript. S.C.B. provided and annotated images. B.P.K., K.V.L., A.D.K., N.F., S.C.B., C.A., and D.Y.O. wrote and edited the manuscript.

\section{References}

1 International Agency for Research on Cancer WHO. International Agency for Research on Cancer: Latest global cancer data. Available at: https://www.iarc.fr/en/mediacentre/pr/2018/pdfs/pr263_E.pdf [Last accessed on July 19, 2019]

2 Overman MJ, Lonardi S, Wong KYM, Lenz HJ, Gelsomino F, Aglietta M, Morse MA, Van Cutsem E, McDermott R, Hill A, Sawyer MB, Hendlisz A, Neyns B, Svrcek M, Moss RA, Ledeine JM, Cao ZA, Kamble S, Kopetz S and André T: Durable clinical benefit with nivolumab plus ipilimumab in DNA mismatch repair-deficient/microsatellite instability-high metastatic colorectal cancer. J Clin Oncol 36(8): 773-779, 2018. PMID: 29355075. DOI: 10.1200/JCO.2017.76.9901

3 Le DT, Uram JN, Wang H, Bartlett BR, Kemberling H, Eyring AD, Skora AD, Luber BS, Azad NS, Laheru D, Biedrzycki B, Donehower RC, Zaheer A, Fisher GA, Crocenzi TS, Lee JJ, Duffy SM, Goldberg RM, de la Chapelle A, Koshiji M, Bhaijee F, Huebner T, Hruban RH, Wood LD, Cuka N, Pardoll DM, 
Papadopoulos N, Kinzler KW, Zhou S, Cornish TC, Taube JM, Anders RA, Eshleman JR, Vogelstein B and Diaz LA Jr: PD-1 blockade in tumors with mismatch-repair deficiency. N Engl J Med 372(26): 2509-2520, 2015. PMID: 26028255. DOI: 10.1056/NEJMoa1500596

4 O’Neil BH, Wallmark JM, Lorente D, Elez E, Raimbourg J, Gomez-Roca C, Ejadi S, Piha-Paul SA, Stein MN, Abdul Razak AR, Dotti K, Santoro A, Cohen RB, Gould M, Saraf S, Stein K and Han SW: Safety and antitumor activity of the anti-PD-1 antibody pembrolizumab in patients with advanced colorectal carcinoma. PLoS One 12(12): e0189848, 2017. PMID: 29284010. DOI: 10.1371/journal.pone.0189848

5 Chen EX, Jonker DJ, Loree JM, Kennecke HF, Berry SR, Couture F, Ahmad CE, Goffin JR, Kavan P, Harb M, Colwell B, Samimi S, Samson B, Abbas T, Aucoin N, Aubin F, Koski SL, Wei AC, Magoski NM, Tu D and O'Callaghan CJ: Effect of combined immune checkpoint inhibition vs best supportive care alone in patients with advanced colorectal cancer: the Canadian Cancer Trials Group CO.26 study. JAMA Oncol 6(6): 831-838, 2020. PMID: 32379280. DOI: 10.1001/jamaoncol.2020.0910

6 Marabelle A, Fakih M, Lopez J, Shah M, Shapira-frommer R, Nakagawa K, Chung H, Kindler H, Lopez-martin J, Miller W, Italiano A, Kao S, Piha-paul S, Delord J, Mcwilliams R, Auroragarg D, Chen M, Jin F, Norwood K and Bang Y: Association of tumour mutational burden with outcomes in patients with select advanced solid tumours treated with pembrolizumab in KEYNOTE-158. Annals of Oncology 30: v477-v478, 2020. DOI: 10.1093/annonc/mdz253.018

7 Meiri E, Garrett-mayer E, Halabi S, Mangat P, Shrestha S, Ahn E, Osayameh O, Perla V and Schilsky R: Pembrolizumab (P) in patients (Pts) with colorectal cancer (CRC) with high tumor mutational burden (HTMB): Results from the Targeted Agent and Profiling Utilization Registry (TAPUR) Study. Journal of Clinical Oncology 38(4_suppl): 133-133, 2020. DOI: 10.1200/JCO.2020.38.4_suppl.133

8 Silberman R, F. steiner D, Lo A, Gomez A, Zehnder J, Chu G and Suarez C: Complete and prolonged response to immune checkpoint blockade in POLE-mutated colorectal cancer. JCO Precision Oncology (3): 1-5, 2020. DOI: 10.1200/po.18.00214

9 Wang F, Zhao Q, Wang YN, Jin Y, He MM, Liu ZX and Xu RH: Evaluation of POLE and POLD1 mutations as biomarkers for immunotherapy outcomes across multiple cancer types. JAMA Oncol 5(10): 1504-1506, 2019. PMID: 31415061. DOI: 10.1001/jamaoncol.2019.2963

10 Garmezy B, Gheeya J, Thein K, Pilie P, Wang W, Rodon ahnert J, Shaw K, Meric-bernstam F and Yap T: Correlation of pathogenic POLE mutations with clinical benefit to immune checkpoint inhibitor therapy. Journal of Clinical Oncology 38(15_suppl): 3008-3008, 2020. DOI: 10.1200/JCO.2020. 38.15_suppl.3008

11 Wang C, Gong J, Tu TY, Lee PP and Fakih M: Immune profiling of microsatellite instability-high and polymerase $\varepsilon$ (POLE)mutated metastatic colorectal tumors identifies predictors of response to anti-PD-1 therapy. J Gastrointest Oncol 9(3): 404415, 2018. PMID: 29998005. DOI: 10.21037/jgo.2018.01.09

$12 \mathrm{Wu} \mathrm{X}$, Mao B and Zhang H: The mutation of homologous recombination repair genetics is a potential biomarker for immunotherapy in microsatellite stable colon cancer. Journal of Clinical Oncology 38(15_suppl): 4076-4076, 2020. DOI: 10.1200/JCO.2020.38.15_suppl.4076
13 Bever KM and Le DT: DNA repair defects and implications for immunotherapy. J Clin Invest 128(10): 4236-4242, 2018. PMID: 30272580. DOI: 10.1172/JCI122010

14 Kraya AA, Maxwell KN, Wubbenhorst B, Wenz BM, Pluta J, Rech AJ, Dorfman LM, Lunceford N, Barrett A, Mitra N, Morrissette JJD, Feldman M, Nayak A, Domchek SM, Vonderheide RH and Nathanson KL: Genomic signatures predict the immunogenicity of BRCA-deficient breast cancer. Clin Cancer Res 25(14): 4363-4374, 2019. PMID: 30914433. DOI: 10.1158/1078-0432.CCR-18-0468

15 Balachandran VP, Łuksza M, Zhao JN, Makarov V, Moral JA, Remark R, Herbst B, Askan G, Bhanot U, Senbabaoglu Y, Wells DK, Cary CIO, Grbovic-Huezo O, Attiyeh M, Medina B, Zhang J, Loo J, Saglimbeni J, Abu-Akeel M, Zappasodi R, Riaz N, Smoragiewicz M, Kelley ZL, Basturk O, Australian Pancreatic Cancer Genome Initiative, Garvan Institute of Medical Research, Prince of Wales Hospital, Royal North Shore Hospital, University of Glasgow, St Vincent's Hospital, QIMR Berghofer Medical Research Institute, University of Melbourne, Centre for Cancer Research, University of Queensland, Institute for Molecular Bioscience, Bankstown Hospital, Liverpool Hospital, Royal Prince Alfred Hospital, Chris O’Brien Lifehouse, Westmead Hospital, Fremantle Hospital, St John of God Healthcare, Royal Adelaide Hospital, Flinders Medical Centre, Envoi Pathology, Princess Alexandria Hospital, Austin Hospital, Johns Hopkins Medical Institutes, ARC-Net Centre for Applied Research on Cancer, Gönen M, Levine AJ, Allen PJ, Fearon DT, Merad M, Gnjatic S, Iacobuzio-Donahue CA, Wolchok JD, DeMatteo RP, Chan TA, Greenbaum BD, Merghoub T and Leach SD: Identification of unique neoantigen qualities in longterm survivors of pancreatic cancer. Nature 551(7681): 512-516, 2017. PMID: 29132146. DOI: 10.1038/nature24462

16 Mandal R, Samstein RM, Lee KW, Havel JJ, Wang H, Krishna C, Sabio EY, Makarov V, Kuo F, Blecua P, Ramaswamy AT, Durham JN, Bartlett B, Ma X, Srivastava R, Middha S, Zehir A, Hechtman JF, Morris LG, Weinhold N, Riaz N, Le DT, Diaz LA Jr and Chan TA: Genetic diversity of tumors with mismatch repair deficiency influences anti-PD-1 immunotherapy response. Science 364(6439): 485-491, 2019. PMID: 31048490. DOI: $10.1126 /$ science.aau0447

17 Petrelli F, Ghidini M, Cabiddu M, Pezzica E, Corti D, Turati L, Costanzo A, Varricchio A, Ghidini A, Barni S and Tomasello G: Microsatellite instability and survival in stage ii colorectal cancer: a systematic review and meta-analysis. Anticancer Res 39(12): 6431-6441, 2019. PMID: 31810907. DOI: 10.21873/anticanres. 13857

18 Campbell BB, Light N, Fabrizio D, Zatzman M, Fuligni F, de Borja R, Davidson S, Edwards M, Elvin JA, Hodel KP, Zahurancik WJ, Suo Z, Lipman T, Wimmer K, Kratz CP, Bowers DC, Laetsch TW, Dunn GP, Johanns TM, Grimmer MR, Smirnov IV, Larouche V, Samuel D, Bronsema A, Osborn M, Stearns D, Raman P, Cole KA, Storm PB, Yalon M, Opocher E, Mason G, Thomas GA, Sabel M, George B, Ziegler DS, Lindhorst S, Issai VM, Constantini S, Toledano H, Elhasid R, Farah R, Dvir R, Dirks P, Huang A, Galati MA, Chung J, Ramaswamy V, Irwin MS, Aronson M, Durno C, Taylor MD, Rechavi G, Maris JM, Bouffet E, Hawkins C, Costello JF, Meyn MS, Pursell ZF, Malkin $D$, Tabori $U$ and Shlien A: Comprehensive analysis of hypermutation in human cancer. Cell 171(5): 1042-1056.e10, 2017. PMID: 29056344. DOI: 10.1016/j.cell.2017.09.048 
19 Ahn SM, Ansari AA, Kim J, Kim D, Chun SM, Kim J, Kim TW, Park I, Yu CS and Jang SJ: The somatic POLE P286R mutation defines a unique subclass of colorectal cancer featuring hypermutation, representing a potential genomic biomarker for immunotherapy. Oncotarget 7(42): 68638-68649, 2016. PMID: 27612425. DOI: 10.18632 /oncotarget.11862

20 Blackford AN and Jackson SP: ATM, ATR, and DNA-PK: The trinity at the heart of the DNA damage response. Mol Cell 66(6): 801-817, 2017. PMID: 28622525. DOI: 10.1016/j.molcel. 2017.05.015

21 Corrales L and Gajewski TF: Molecular pathways: targeting the Stimulator of Interferon Genes (STING) in the immunotherapy of cancer. Clin Cancer Res 21(21): 4774-4779, 2015. PMID: 26373573. DOI: 10.1158/1078-0432.CCR-15-1362

22 Harrington K, Brody J, Ingham M, Strauss J, Cemerski S, Wang M, Tse A, Khilnani A, Marabelle A and Golan T: Preliminary results of the first-in-human (FIH) study of MK-1454, an agonist of stimulator of interferon genes (STING), as monotherapy or in combination with pembrolizumab (pembro) in patients with advanced solid tumors or lymphomas. Annals of Oncology 29: viii712, 2020. DOI: 10.1093/annonc/mdy424.015

23 Härtlova A, Erttmann SF, Raffi FA, Schmalz AM, Resch U, Anugula S, Lienenklaus S, Nilsson LM, Kröger A, Nilsson JA, Ek $\mathrm{T}$, Weiss $\mathrm{S}$ and Gekara NO: DNA damage primes the type I interferon system via the cytosolic DNA sensor STING to promote anti-microbial innate immunity. Immunity 42(2): 332343, 2015. PMID: 25692705. DOI: 10.1016/j.immuni.2015.01.012

24 Zhang Q, Green MD, Lang X, Lazarus J, Parsels JD, Wei S, Parsels LA, Shi J, Ramnath N, Wahl DR, Pasca di Magliano M, Frankel TL, Kryczek I, Lei YL, Lawrence TS, Zou W and Morgan MA: Inhibition of ATM increases interferon signaling and sensitizes pancreatic cancer to immune checkpoint blockade therapy. Cancer Res 79(15): 3940-3951, 2019. PMID: 31101760. DOI: 10.1158/0008-5472.CAN-19-0761

25 Chen Y, Chen G, Li J, Huang YY, Li Y, Lin J, Chen LZ, Lu JP, Wang YQ, Wang CX, Pan LK, Xia XF, Yi X, Chen CB, Zheng $\mathrm{XW}$, Guo ZQ and Pan JJ: Association of tumor protein p53 and ataxia-telangiectasia mutated comutation with response to immune checkpoint inhibitors and mortality in patients with nonsmall cell lung cancer. JAMA Netw Open 2(9): e1911895, 2019. PMID: 31539077. DOI: 10.1001/jamanetworkopen.2019.11895

26 Chae YK, Anker JF, Oh MS, Bais P, Namburi S, Agte S, Giles FJ and Chuang JH: Mutations in DNA repair genes are associated with increased neoantigen burden and a distinct immunophenotype in lung squamous cell carcinoma. Sci Rep 9(1): 3235, 2019. PMID: 30824826. DOI: 10.1038/s41598-01939594-4
27 Tumeh PC, Hellmann MD, Hamid O, Tsai KK, Loo KL, Gubens MA, Rosenblum M, Harview CL, Taube JM, Handley N, Khurana N, Nosrati A, Krummel MF, Tucker A, Sosa EV, Sanchez PJ, Banayan N, Osorio JC, Nguyen-Kim DL, Chang J, Shintaku IP, Boasberg PD, Taylor EJ, Munster PN, Algazi AP, Chmielowski B, Dummer R, Grogan TR, Elashoff D, Hwang J, Goldinger SM, Garon EB, Pierce RH and Daud A: Liver metastasis and treatment outcome with anti-PD-1 monoclonal antibody in patients with melanoma and NSCLC. Cancer Immunol Res 5(5): 417-424, 2017. PMID: 28411193. DOI: 10.1158/2326-6066.CIR-16-0325

28 Wolchok JD, Hoos A, O’Day S, Weber JS, Hamid O, Lebbé C, Maio M, Binder M, Bohnsack O, Nichol G, Humphrey R and Hodi FS: Guidelines for the evaluation of immune therapy activity in solid tumors: immune-related response criteria. Clin Cancer Res 15(23): 7412-7420, 2009. PMID: 19934295. DOI: 10.1158/1078-0432.CCR-09-1624

29 Seymour L, Bogaerts J, Perrone A, Ford R, Schwartz LH, Mandrekar S, Lin NU, Litière S, Dancey J, Chen A, Hodi FS, Therasse P, Hoekstra OS, Shankar LK, Wolchok JD, Ballinger M, Caramella C, de Vries EGE and RECIST working group: iRECIST: guidelines for response criteria for use in trials testing immunotherapeutics. Lancet Oncol 18(3): e143-e152, 2017. PMID: 28271869. DOI: 10.1016/S1470-2045(17)30074-8

30 Andtbacka RH, Ross M, Puzanov I, Milhem M, Collichio F, Delman KA, Amatruda T, Zager JS, Cranmer L, Hsueh E, Chen L, Shilkrut M and Kaufman HL: Patterns of clinical response with talimogene laherparepvec (T-VEC) in patients with melanoma treated in the OPTiM phase iii clinical trial. Ann Surg Oncol 23(13): 4169-4177, 2016. PMID: 27342831. DOI: 10.1245/s10434-016-5286-0

31 Hamid O, Ismail R and Puzanov I: Intratumoral immunotherapyupdate 2019. Oncologist 25(3): e423-e438, 2020. PMID: 32162802. DOI: 10.1634/theoncologist.2019-0438

32 Lee HY, Lee KS, Ahn MJ, Hwang HS, Lee JW, Park K, Ahn JS, Kim TS, Yi CA and Chung MJ: New CT response criteria in non-small cell lung cancer: proposal and application in EGFR tyrosine kinase inhibitor therapy. Lung Cancer 73(1): 63-69, 2011. PMID: 21093094. DOI: 10.1016/j.lungcan.2010.10.019

33 Nishino $M$, Hatabu $H$ and Hodi FS: Imaging of cancer immunotherapy: current approaches and future directions. Radiology 290(1): 9-22, 2019. PMID: 30457485. DOI: 10.1148/radiol.2018181349

Received April 3, 2021

Revised April 14, 2021

Accepted May 7, 2021 